Int. J. Electrochem. Sci., 13 (2018) $6112-6125$

International Journal of

ELECTROCHEMICAL

SCIENCE

$\underline{\text { www.electrochemsci.org }}$

\title{
Proton Ion Conducting Solid Polymer Electrolytes Based on Chitosan Incorporated with Various Amounts of Barium Titanate $\left(\mathrm{BaTiO}_{3}\right)$
}

\author{
Shujahadeen B. Aziz ${ }^{1,2, *}$, Wrya O. Karim ${ }^{3}$, Karwan W. Qadir ${ }^{4,5}$, Qayyum Zafar ${ }^{6}$ \\ ${ }^{1}$ Advanced Polymeric Materials Research Lab., Department of Physics, College of Science, University \\ of Sulaimani, Qlyasan Street, Sulaimani, Kurdistan Regional Government-Iraq \\ ${ }^{2}$ Komar Research Center (KRC), Komar University of Science and Technology, Sulaimani, 46001, \\ Kurdistan Regional Government, Iraq \\ ${ }^{3}$ Department of Chemistry, College of Science, University of Sulaimani, Qlyasan Street, Sulaimani, \\ Kurdistan Regional Government-Iraq \\ ${ }^{4}$ Department of Physics, College of Education, Salahaddin University-Hawler, 44001 Erbil, Kurdistan \\ Region, Iraq. \\ ${ }^{5}$ Physics Education Department, Faculty of Education, Ishik University, 44001 Erbil, Iraq. \\ ${ }^{6}$ Department of Physics, Government College University, Lahore 54000, Pakistan. \\ *E-mail: shujaadeen78@yahoo.com, shujahadeenaziz@gmail.com
}

doi: $10.20964 / 2018.06 .38$

Received: 15 February 2018 / Accepted: 10 April 2018 / Published: 10 May 2018

Here the impact of barium titanate $\left(\mathrm{BaTiO}_{3}\right)$ nano filler on both electrical and dielectric properties of proton conducting solid polymer electrolytes based on chitosan have been discussed using AC impedance spectroscopy. The impedance data reveals that up to $3 \mathrm{wt}$. $\%$ of $\mathrm{BaTiO}_{3}$, the conductivity shows an increaseAt low frequency, the maximum values for both dielectric constant and dielectric loss have been observed. Further distinguishable peaks have been observed in the imaginary part of electric modulus while no such peaks were observed in dielectric loss spectra From the Argand plots, the relaxation processes was interpreted. At low temperature, the DC conductivity versus reciprocal of temperature obeys the Arrhenius equation and at the high temperature, the curvature was obtained as an evidence for ion transport process with the aid of polymer segmental motion. Grotthus mechanism was used to interpret the conductivity behaviors of the samples.

Keywords: Polymer Composite, barium titanate, Proton Ion Conductor, Relaxation process, Arhenius and VTF equations

\section{$\underline{\text { FULL TEXT }}$}


(C) 2018 The Authors. Published by ESG (www.electrochemsci.org). This article is an open access article distributed under the terms and conditions of the Creative Commons Attribution license (http://creativecommons.org/licenses/by/4.0/). 